\title{
The psychiatrist, the patient, their relationship and the movies
}

\author{
Jacqueline M. Atkinson
}

Diagnosing a man who has travelled back from the future and who, in the present, speaks of the future as the past causes no problems: paranoid schizophrenia. Thus is Bruce Willis misunderstood in Twelve Monkeys (1995). Neither this, nor Brad Pitt as a patient with schizophrenia should distract us; once more we have a film in which a psychiatrist develops a dubious relationship with a patient. Despite evidence of the destructive impact on patients (Russell, 1993; Jehu, 1994), in films it has become almost normal.

Unethical relationships have been depicted in films of every genre; for example with male psychiatrists in Carefree (1938), Tender is the Night (1961) and Lilith (1964); and female psychiatrists in Spellbound (1945), They Might be Giants (1971), The Man who Loved Women (1983) and $\mathrm{Mr}$ Jones (1994). Female therapists working with the police are equally susceptible, for example: Basic Instinct (1992) and Knight Moves (1992). Neither are patients' families immune. In Prince of Tides (1991) the married female psychiatrist has an affair with a patient's married brother, making him a patient in the process. In both Final Analysis (1992) and Blindfold (1966) male psychiatrists develop relationships with patients' sisters.

Rarely are approaches from patient or therapist rejected. Examples come from an unusual genre. In Wild in the Country (1961) a therapist rejects the young Elvis Presley's advances, while in Follow that Dream (1961) a naive Elvis does not notice the advances of a psychologist.

In some films an older (and wiser?) psychiatrist advises against the relationship. In Spellbound. Michael Chekhov counsels Ingrid Bergman, stressing countertransference. Such advice is ignored and the audience is expected to side with the psychiatrist, in the name of 'love'. By invoking countertransference the argument is based on the relationship not being 'real', rather than any damage it may do to the patient. Gabbard \& Gabbard (1987) discuss doctorpatient relationships in films predominately in these terms. Such arguments require audiences to be relatively sophisticated in respect of psychoanalytic theory.
Rarely is the relationship seen as posing a serious problem for patients. Lovesick (1983) is described in the TV Times as "Sweet romantic comedy about psychiatrist Dudley Moore's entirely understandable obsession with charming patient Elizabeth McGovern". Schneider (1985) describes Moore's psychiatrist as a Dr Dippy who becomes a Dr Wonderful, treating psychotic street-people rather than middle-class neurotics. There is no mention of his sexual relationship with a patient. Where does this fit with being $\mathrm{Dr}$ Wonderful?

Jonathan Ross (1993) reminds us that sex with a doctor is one of the five basic plots in porn films, involving "a betrayal of some professional ... code of behaviour, adding, . . . a little extra spice to the proceedings". Is this 'extra spice' the only reason for the relationship in mainstream films?

No one would deny that relationships do sometimes develop between therapists and patients, nor that such relationships are unethical, in different ways damaging to both parties and are about the abuse of power (Russell, 1993; Jehu, 1994). The latter is not usually conveyed in the films, especially as so many are between female therapists and male patients which does not reflect reality (Russell, 1993; Jehu, 1994).

The Gabbards (1987) suggest that the reason is to deny the power of female professionals. Portrayed as having unsatisfactory personal lives, the underlying message is that they have given up being women to become doctors but the male patient is able to make them women again. Even when they are aware of the impact of the relationship on their careers it makes no difference. Julie Andrews acknowledges the conflict, telling Burt Reynolds (The Man Who Loved Women, 1983) that he will gain a lover but lose a therapist. Power still seems to reside with the men.

This relationship also denies any real therapeutic effect for psychiatry. What the patients are lacking is love (or sex) and this the therapist provides, not specialised knowledge or skills. This undermines psychiatry as a medical speciality and devalues patients and their suffering. Mental illness becomes no more than an inability 
to form close personal relationships. It leads us to believe that $M r$ Jones's out-of-control manic and depresssive episodes are better treated by an affair with his psychiatrist than by lithium. It diminishes his pain. Both these reasons may, however, explain why more films about doctorpatient relationships feature a psychiatrist than other specialities.

We accept a degree of 'artistic licence' in films made as entertainment and maybe the unethical relationship is simply an unusual love story. The professional relationship is a barrier to 'true love' rather than a protection for vulnerable patients (and, indeed, vulnerable therapists). Ethics, it seems, are not only no match for love, they should not be. Patients and other vulnerable people watching such films must be worried by the message that sex between therapist and patient is a good thing as this denies the reality of what they know. Patients are being exploited and these films are about abuse.

\section{References}

GABBARD. K. \& GABBARD, G. O. (1987) Psychiatry and the Cinema. Chicago: University of Chicago Press.

JeHU. D. (1994) Patients as Victims. Sexual Abuse in Psychotherapy and Counselling. Chichester: Wiley.

Ross, J. (1993) The Incredibly Strange Fum Book. London: Simon \& Schuster.

Russeu., J. (1993) Out of Bounds. Sexual Exploitation in Counselling and Therapy. London: Sage.

SCHNEIDER. I. (1985) The psychiatrist in the movies: the first fifty years. In Psychoanalytic Study of Literature leds J. Reppen \& M. Charney). Hillsdale, NJ: Analytic Press.

Jacqueline M. Atkinson, Senior Lecturer, University of Glasgow, Department of Public Health, 2 Lilybank Gardens, Glasgow G12 8RZ 